\title{
The Organizational Role Stress among the Doctors of Government and Private Medical College in Nagpur
} Dr. Gayathri Band

Assistant Professor, Shri Ramdeobaba College of Engineering and Management, Nagpur Email:bandgs@rknec.edu

\author{
Received: $20^{\text {th }}$ September 2018, Accepted: $11^{\text {th }}$ October 2018, Published: $31^{\text {st }}$ October 2018
}

\begin{abstract}
The organizational stress is said to be the cause of all those factors in the organization that causes stress to an individual employee and have negative organizational ill effects. Findings of the present study revealed that Health care Professionals are suffering from organizational role stress. The mean value 65.83 for total ORS private is quite high. The level of stress on Inter Role Distance (IRD) is the highest (9.02), followed by Role stagnation (7.55). Along with these two stressors (RO) and (RIn) is above 7, the level of stress on three stressors i.e. Role Erosion, personal inadequacy and Role expectation conflicts is above 6, which is again on a higher side. The mean value is 77.84 for total ORS public is quite high comparatively. The level of stress on role stagnation (RS) is the highest (9.81), followed by Role expectation conflict (7.55). Along with these two stressors (RE) and (IRD) is above 7, the level of stress on three stressors i.e. Resources inadequacy, personal inadequacy and Role expectation inadequacy is above 7, which is again on a higher side.
\end{abstract}

Keywords

Organizational Role Stress, Inter Role Distance, Role Stagnation, Role Expectation Conflict, Role Erosion, Role Overload, Role Isolation, Personal Inadequacy, Self-Role Distance, Role Ambiguity, Resource Inadequacy

\section{Introduction}

The organizational stress is said to be the cause of all those factors in the organization that causes stress to an individual employee and have negative organizational ill effects. The employee stress may cause absenteeism, burn out, performance issues, lack of trust, motivation etc. There might be lot of factors causing organizational change such as organizational structure, leadership style, demand of task \& roles, quality of work, change in businesses processes etc. The potential threats have basically shifted from short-term decision making to long-term decision making. All the negative experiences an individual employee experiences at work increases the probability for developing work related stress-disorders. All stress related to workplace situations are known as Organizational Role Stress.

An employee who is exposed to Organizational Role Stress for longer periods of time are likely to get burnt-out, decreased overall performance and it also affects co-workers morale negatively (Ratna et al., 2013, p. 361). Ratna et al. (2013, p.361) emphasizes that Organizational Role Stress is present in all types of organizations. Apart from serious illness of individuals, Organizational Role Stress decreases employee productivity, which affects the overall competiveness of the organization (Bano et al., 2011, pp. 109-110). Longer exposures to Organizational Role Stress may also decrease the quality of services and products, poor client relationships, dysfunctional work climate and high labor turnover (Bano et al., 2011, pp. 109-110).

Udai Pareek is considered to be a pioneer in the field of Organizational Role Stress; he developed a framework including ten different stressors to explore how an individual perceive Organizational Role Stress. They are as follows: Inter Role Distance (IRD), Role Stagnation (RS), Role Expectation Conflict (RES), Role Erosion (RE), Role Overload (RO), Role Isolation (RI), Personal Inadequacy (PI), Self-Role Distance (SRD), Role Ambiguity (RA) and Resource Inadequacy (RIN) (Pareek, 1983 cited in Ratna et al., 2013 p. 366). The framework will reveal the potential Organizational Role Stress in among the employees in the Information Processing Companies of Nagpur and study the effect of ORS factors on the overall level of stress of the employees. The study is to find the effect of the ten stressors on the overall level of stress of the employees and identify the important causes of stress in the organization

\section{Material \& Methods}

The study is regarding the Effect of ten factors of Organizational Role Stress on the overall stress level of the doctors of Government and Private Medical College in Nagpur City. Simple Random sampling technique was used to identify responses for the study. Sample size is 240 doctors (junior residential i.e. Doctors, Doing MS or MD) from both the medical college i.e. private and public. 120 doctors of private organization including all the departments i.e. dental, physiotherapy, MBBS. 120 doctors of private organization including all the departments i.e. dental, physiotherapy, MBBS 
Udai Pareek standardized ORS questionnaire was used for evaluating the organizational stress among the employees on a Likert type scale, where 0 indicated minimum agreement and 4 indicated maximum agreement as given below

0 - if you never or rarely feel this way.

1 - if you occasionally ( a few times) feel this way.

2 - if you sometimes feel this way.

3 - if you frequently feel this way.

4 - if you very frequently or always feel this way.

\section{Result \& Discussion}

Comparative study of stress measurement in doctors of government medical college and private medical college, Nagpur.

\begin{tabular}{|c|c|c|c|c|c|c|c|c|c|c|c|}
\hline \multirow[t]{2}{*}{ STREESORS } & \multirow[t]{2}{*}{ MEAN } & \multirow[t]{2}{*}{ STD.DEV } & \multirow[t]{2}{*}{ RANK } & \multicolumn{2}{|c|}{$\begin{array}{l}\text { LOW } \\
\text { STRESS }\end{array}$} & \multicolumn{2}{|c|}{$\begin{array}{c}\text { LOW } \\
\text { MEDIUM } \\
\text { STRESS }\end{array}$} & \multicolumn{2}{|c|}{$\begin{array}{c}\text { HIGH } \\
\text { MEDIUM } \\
\text { STRESS }\end{array}$} & \multicolumn{2}{|c|}{$\begin{array}{l}\text { VERY HIGH } \\
\text { STRESS }\end{array}$} \\
\hline & & & & NOS & $\%$ & NOS & $\%$ & NOS & $\%$ & NOS & $\%$ \\
\hline IRD & 9.02 & 4.63 & 1 & 34 & 28.33 & 42 & 35.00 & 33 & 27.50 & 11 & 9.17 \\
\hline $\mathbf{R S}$ & 7.55 & 4.01 & 2 & 44 & 36.67 & 48 & 40.00 & 25 & 20.83 & 3 & 2.50 \\
\hline REC & 6.67 & 3.64 & 7 & 46 & 38.33 & 56 & 46.67 & 18 & 15.00 & 0 & 0.00 \\
\hline $\mathbf{R E}$ & 6.93 & 3.53 & 5 & 41 & 34.17 & 61 & 50.83 & 13 & 10.83 & 5 & 4.17 \\
\hline RO & 7.37 & 3.62 & 3 & 36 & 30.00 & 57 & 47.50 & 24 & 20.00 & 3 & 2.50 \\
\hline RI & 5.97 & 3.51 & 8 & 62 & 51.67 & 40 & 33.33 & 18 & 15.00 & 0 & 0.00 \\
\hline PI & 6.69 & 3.98 & 6 & 54 & 45.00 & 43 & 35.83 & 21 & 17.50 & 2 & 1.67 \\
\hline SRD & 2.98 & 3.71 & 10 & 44 & 36.67 & 54 & 45.00 & 19 & 15.83 & 3 & 2.50 \\
\hline $\mathbf{R A}$ & 5.57 & 3.64 & 9 & 67 & 55.83 & 41 & 34.17 & 11 & 9.17 & 1 & 0.83 \\
\hline RIN & 7.08 & 3.5 & 4 & 43 & 35.83 & 56 & 46.67 & 19 & 15.83 & 2 & 1.67 \\
\hline TOTAL & 65.83 & 37.77 & & 47.1 & 39.25 & 49.8 & 41.5 & 20.1 & 16.75 & 3 & 2.5 \\
\hline
\end{tabular}

Findings of the present study revealed that Health care Professionals are suffering from organizational role stress. The mean value 65.83 for total ORS private is quite high. The level of stress on Inter Role Distance (IRD) is the highest (9.02), followed by Role stagnation (7.55). Along with these two stressors (RO) and (RIn) is above 7, the level of stress on three stressors i.e. Role Erosion, personal inadequacy and Role expectation conflicts is above 6 , which is again on a higher side.

In order to investigate further, the ORS scores on various stressors have been classified in four categories; namely, Low stress group (0-5), medium stress group (6-10), medium high stress group (11-15), and the very high stress group (16-20). It can be pointed out that (41.5\%) of doctors experience low medium level of stress, followed by low stress level $(39.25 \%) ; 16.75 \%$ doctors fall under the category of high medium stress level, contributing to a high total ORS score of 71.20. Only $(2.5 \%)$ of doctors fall under the category of very high stress group. The high score of inter role distance in doctors may be due to the nature of their work. Their day in the hospital starts with attending the patients, inspecting their respective wards, attend academic lectures and work during nights at least twice a week and then attend their familial demands as well.

Total ORS Score of Doctors of Public.

\begin{tabular}{|c|c|c|c|c|c|c|c|c|c|c|c|}
\hline $\begin{array}{l}\text { STREES } \\
\text { ORS }\end{array}$ & MEAN & STD.DEV & RANK & \multicolumn{2}{l}{ LOW STRESS } & \multicolumn{2}{l|}{$\begin{array}{l}\text { LOW MEDIUM } \\
\text { STRESS }\end{array}$} & \multicolumn{2}{|c|}{$\begin{array}{c}\text { HIGH } \\
\text { MEDIUM } \\
\text { STRESS }\end{array}$} & \multicolumn{2}{|l|}{$\begin{array}{l}\text { VERY HIGH } \\
\text { STRESS }\end{array}$} \\
\hline & & & & NO & $\%$ & NO & $\%$ & NO & $\%$ & NO & $\%$ \\
\hline IRD & 7.9 & 3.39 & 4 & 31 & 25.83 & 58 & 48.33 & 30 & 25 & 1 & 0.83 \\
\hline RS & 9.81 & 3.96 & 1 & 20 & 16.67 & 51 & 42.50 & 38 & 31.67 & 11 & 9.17 \\
\hline REC & 8.26 & 3.42 & 2 & 24 & 20.00 & 66 & 55.00 & 27 & 22.5 & 3 & 2.50 \\
\hline RE & 7.96 & 3.88 & 3 & 32 & 26.67 & 59 & 49.17 & 25 & 20.83 & 4 & 3.33 \\
\hline RO & 7.37 & 3.09 & 8 & 31 & 25.83 & 71 & 59.17 & 16 & 13.33 & 2 & 1.67 \\
\hline RI & 7.49 & 3.58 & 7 & 39 & 32.50 & 57 & 47.50 & 21 & 17.5 & 3 & 2.50 \\
\hline PI & 7.63 & 3.24 & 6 & 31 & 25.83 & 67 & 55.83 & 19 & 15.83 & 3 & 2.50 \\
\hline SRD & 6.55 & 2.88 & 10 & 45 & 37.50 & 67 & 55.83 & 8 & 6.67 & 0 & 0.00 \\
\hline RA & 7.2 & 2.95 & 9 & 32 & 26.67 & 76 & 63.33 & 12 & 10 & 0 & 0.00 \\
\hline RIN & 7.67 & 2.8 & 5 & 27 & 22.50 & 79 & 65.83 & 11 & 9.17 & 3 & 2.50 \\
\hline TOTAL & $\mathbf{7 7 . 8 4}$ & $\mathbf{3 3 . 1 9}$ & & $\mathbf{3 1 . 2}$ & $\mathbf{2 6}$ & $\mathbf{6 5 . 1}$ & $\mathbf{5 4 . 2 5}$ & $\mathbf{2 0 . 7}$ & $\mathbf{1 7 . 2 5}$ & $\mathbf{3}$ & $\mathbf{2 . 5}$ \\
\hline
\end{tabular}


Findings of the present study revealed that Health care Professionals are suffering from organizational role stress. The mean value is 77.84 for total ORS public is quite high comparatively. The level of stress on role stagnation (RS) is the highest (9.81), followed by Role expectation conflict (7.55). Along with these two stressors (RE) and (IRD) is above 7, the level of stress on three stressors i.e. Resources inadequacy, personal inadequacy and Role expectation inadequacy is above 7, which is again on a higher side.

In order to investigate further, the ORS scores on various stressors have been classified in four categories; namely, Low stress group (0-5), medium stress group (6-10), medium high stress group (11-15), and the very high stress group (16-20). It can be pointed out that (54.25\%) of doctors experience low medium level of stress, followed by low stress level $(26 \%) ; 17.25 \%$ doctors fall under the category of high medium stress level, contributing to a high total ORS score of 77.84 . Only $(2.5 \%)$ of doctors fall under the category of very high stress group. The high score of role stagnation in doctors may be due to the nature of their work. Their day in the hospital starts with attending the patients, inspecting their respective wards, attend academic lectures and work during nights at least twice a week and then attend their familial demands as well.

\section{Conclusion}

Level of Stress in Both the Organization

\begin{tabular}{|l|c|c|c|c|c|c|c|c|c|c|c|c|}
\hline STRESSORS & IRD & RS & REC & RE & RO & RI & PI & SRD & RA & RIN & TOTAL & RANK \\
\hline PRIVATE & 9.02 & 7.55 & 6.67 & 6.93 & 7.37 & 5.97 & 6.69 & 2.98 & 5.57 & 7.08 & 65.83 & 2 \\
\hline PUBLIC & 7.9 & 9.81 & 8.26 & 7.96 & 7.37 & 7.49 & 7.63 & 6.55 & 7.2 & 7.67 & 77.84 & 1 \\
\hline
\end{tabular}

$>\quad$ According to ORS the total of all the factors is highest in public organization i.e. 77.84 .

$>\quad$ The total of all the stressors is high in public organization comparing to private organization

$>\quad$ The mean value is 65.83 for total ORS in private is quite high where the mean value of public is 77.84 for total ORS is comparatively more higher than the private.

In private \& public maximum number of doctors are under medium stress level. So it can be conclude that the level of stress of all the stressors are equal.

The level of stress in Role stagnation (RS) is the highest (9.81) in public where the level of stress in Inter Role Distance (IRD) is private highest (9.02), so here it can be conclude that in public organisation most of the doctors feel stagnant in their role and in private most of the doctors are under inter role distance stressor.

$>\quad$ In private the doctors of the age group (32-37 yrs) comes under the inter role distance stressors while in public the doctors of age group (32-37 yrs) undergoes the stressors of role stagnant and role erosion so, it can be conclude that the doctors of public and private are under different stressors with respect to the age.

$>\quad$ The doctors of public organization having the experience of (0-5 yrs) are having more stress in them while the doctors of private organization having the experience of $(5-10 \mathrm{yrs})$ are under more stress.

According to ORS total stressors the doctors who are divorcee are having more stress comparing to the doctors of private organization who are married.

\section{References}

1. Agrawal, R. K. \& Majupuria, A. (2010). Role stress among women in the Indian information technology sector. International Journal of Indian Culture and Business Management. Vol. 3 (5), pp. $577-591$.

2. Aziz, M. (2004). Role stress among women in the Indian information technology sector.Women in Management Review. Vol. 19 (7), pp. 356-363.

3. Bano, B., Gopalan, M., Talib, P. \& Sundarakani, B. (2011). Organizational role stress: the conceptual framework. International Journal of Logistics Economics and Globalization. Vol. 3 (2), pp. 102-115.

4. Bano, B. \& Jha, R. K. (2012). Organizational Role Stress Among Public and Private Sector Employees: A Comparative Study. The Lahore Journal of Business. Vol. 1 (1), pp. 23-36.

5. Chauhan, A. P. (2014). Organizational Role Stress. International Journal of Advanced Research in Management and Social Sciences. Vol. 3 (2), pp. 154-171.

6. Coverman, S. (1989). Role Overload, Role Conflict, and Stress: Addressing Consequences of Multiple Role Demands. Social Forces. Vol. 67 (4), pp. 965-982.

7. Kahn, R. L., Wolfe, D. M., Quinn, R. P., Diedrick, J. S. \& Rosenthal, R. A. (1964). Organizational Stress: Studies in Role Conflict and Ambiguity. New York: Wiley

8. Rakesh, R. (2012). Organizational Role Stress In Relationship With Social Support Of Industrial Employees. Indian Streams Research Journal. Vol. 2 (7), p. 1108 (pp. 1-7).

9. Ratna, R., Chawla, S. and Mittal, R. (2013). Organizational role stress: level of stress, major stressor and its differences. International Journal of Indian Culture and Business Management. Vol. 7 (3), pp. 359-383. 
10. Sinha, V. \& Subramanian, K. S. (2012). Organizational role stress across three managerial levels: A comparative study. Global Business and Organizational Excellence. Vol. 31 (5), pp. 70-77.

11. Srivastav A. K. (2006). Coping with Stress in Organizational Roles. Indian Journal of Industrial Relations, Vol. 42 (1), pp. 110-128.

12. Waddar, M. S. \& Aminabhavi, V. A. (2012). Emotional Labor and Organizational Role Stress: A Study of Aircraft Employees. Global Business Review. Vol. 13 (3), pp. 383- 392.

13. Udai Pareekh and Surabhi Purohit., 2010. Training instrument in HRD and OD: edition., Tata McGraw-Hill

14. Hussain., 2001. Perceived Stress Effects and Psychological Well-being among Doctors. Stress Research and Stress Management, 1, pp. 37-58. 